\title{
Tetramethylammonium Difluoro(oxalato)borate as Novel Electrolyte for Electric Double-Layer Capacitors
}

\author{
Noritoshi Nanbu, ${ }^{*}$ Keita SuzukI, Takahito EBINA, Hiroyuki UnO, and Yukio SASAKI
}

Department of Nanochemistry, Faculty of Engineering, Tokyo Polytechnic University (1583 Iiyama, Atsugi, Kanagawa 243-0297, Japan)

Received February 14, 2007 ; Accepted July 3, 2007

\begin{abstract}
The use of an asymmetric borate anion, difluoro(oxalato)borate ( $\mathrm{DFOB}^{-}$), improves the solubility of the tetramethylammonium salt in propylene carbonate (PC) and the capacitances of electric double-layer capacitors (EDLCs). Electric conductivity of the PC solution containing tetramethylammonium difluoro(oxalato)borate (TMADFOB) was slightly lower than that obtained for tetraethylammonium tetrafluoroborate $\left(\mathrm{TEABF}_{4}\right)$, but higher than those obtained for tetramethylammonium bis(oxalato)borate (TMABOB) and tetraethylammonium bis(oxalato)borate (TEABOB). The gravimetric capacitances of measurement cells increased with decreasing the ion sizes of the electrolytes. The PC solution containing TMADFOB afforded the highest gravimetric capacitance.
\end{abstract}

Key Words : Electric Double-Layer Capacitor, Electrolyte, Tetramethylammonium Cation, Asymmetric Anion

\section{Introduction}

Increasing attention has recently paid to the utilization of electric double-layer capacitors (EDLCs) for hybrid electric vehicles. Tetraethylammonium tetrafluoroborate $\left(\mathrm{TEABF}_{4}\right)$ is commonly used as an electrolyte for the EDLC. The use of the smallest quaternary ammonium ion, tetramethylammonium ion $\left(\mathrm{TMA}^{+}\right)$, can increase the number of ions accumulated in pores of an activated carbon electrode and bring about high capacitance. Regretably, the solubility of tetramethylammonium tetrafluoroborate $\left(\mathrm{TMABF}_{4}\right)$ in propylene carbonate $(\mathrm{PC})$ is as low as $0.1 \mathrm{~mol} \mathrm{dm}^{-3}$ at $25^{\circ} \mathrm{C}$. ${ }^{1}$ The combination of $\mathrm{TMA}^{+}$ and a larger anion, bis(oxalato)borate $\left(\mathrm{BOB}^{-}\right)$, improves the solubility in the PC $\left.\left(0.9 \mathrm{~mol} \mathrm{dm}^{-3}\right)\right)^{2,3)}$ The use of a small asymmetric ion as a counter anion should further decrease the crystal lattice energy of the electrolyte and hence can increase the degree of ionic dissociation. Electric conductivity of the electrolyte solution is expected to become higher than that of the solution containing the corresponding symmetric chelatoborate, tetramethylammonium bis(oxalato)borate (TMABOB).

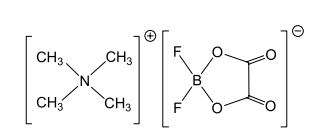

Tetramethylammonium difluoro(oxalato)borate (TMADFOB)

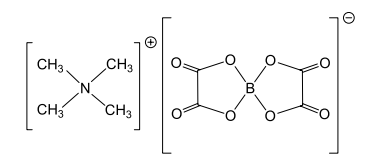

Tetramethylammonium bis(oxalato)borate (TMABOB)

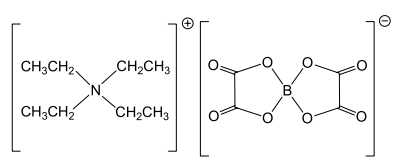

Tetraethylammonium bis(oxalato)borate (TEABOB)
In this paper we report the use of tetramethylammonium difluoro(oxalato)borate (TMADFOB) as a novel electrolyte for EDLCs. TMADFOB has the potential of improving both the solubility in $\mathrm{PC}$ and the capacitance of EDLCs.

\section{Experimental}

The synthesis of TMABOB and TEABOB was previously reported. ${ }^{2-4)}$ TMADFOB was synthesized on the basis of the literature describing the production of lithium difluoro(oxalato)borate. ${ }^{5)}$ Tetramethylammonium tetrafluoroborate $\left(\mathrm{TMABF}_{4}\right)$ was allowed to react with oxalic acid $\left((\mathrm{COOH})_{2}\right)$ in the presence of silicon chloride $\left(\mathrm{SiCl}_{4}\right)$. A mixture of oxalic acid $(26.5 \mathrm{~g}, 0.29 \mathrm{~mol})$, $\mathrm{TMABF}_{4}(67.69 \mathrm{~g}, 0.42 \mathrm{~mol})$, and acetonitrile (AN, $\left.500 \mathrm{ml}\right)$ was stirred in a $1 \mathrm{dm}^{3}$ reactor. $\mathrm{SiCl}_{4}(25 \mathrm{~g}, 0.15 \mathrm{~mol})$ was added dropwise to the AN solution. An Ar gas was passed through the reactor cooled in an ice bath. After stirred overnight, the AN solution was allowed to evaporate under reduced pressure. The crude product was purified by fractional recrystallization from a mixture of AN and ethyl acetate, and the purified TMADFOB was dried in vacuo at $70{ }^{\circ} \mathrm{C}$ for $48 \mathrm{~h}$. TMADFOB was obtained in a yield of $45 \%$. The results of the elemental analysis were in good agreement with the calculated values: calcd. for TMADFOB: C, 34.16; H, 5.73; N, 6.64, found for TMADFOB: C, 34.28; H, 6.21; N, 6.99. The TMADFOB was also identified by means of ${ }^{1} \mathrm{H},{ }^{13} \mathrm{C},{ }^{19} \mathrm{~F}$, and ${ }^{11} \mathrm{~B}$ NMR spectroscopy (JEOL, JNM-LA500). The results are as follows: ${ }^{1} \mathrm{H}$ NMR (TMS/DMSO, $500.00 \mathrm{MHz}$ ): $\delta 3.16$ (s, 3H). ${ }^{13} \mathrm{C}$ NMR (TMS/DMSO, $125.65 \mathrm{MHz}$ ): $\delta 54.36,159.23 .{ }^{19} \mathrm{~F}$ $\mathrm{NMR}\left(\mathrm{CF}_{3} \mathrm{COOD} / \mathrm{D}_{2} \mathrm{O}, 470.40 \mathrm{MHz}\right): \delta-148.86 .{ }^{11} \mathrm{~B} \mathrm{NMR}$ $\left(\mathrm{NaBH}_{4} / \mathrm{D}_{2} \mathrm{O}, 160.35 \mathrm{MHz}\right): \delta-15.67$.

$\mathrm{PC}$ as a solvent and $\mathrm{TEABF}_{4}$ as a reference standard for an electrolyte were used as received (Kishida, bat- 
tery grade). The preparation of electrolytic solutions and the fabrication of three-electrode electrolysis and measurement cells were carried out in an argon-filled glove box system made by VAC. Activated carbon electrodes contained 82 mass \% activated charcoal (average surface area $866 \mathrm{~m}^{2} \mathrm{~g}^{-1}$, average pore size: $2.975 \mathrm{~nm}$ ), 9 mass $\%$ acetylene black as the conductor, and 9 mass $\%$ poly(tetrafluoroethylene) as the binder.

The apparatus and techniques for measurements are essentially the same as those previously reported. ${ }^{2-4)}$

\subsection{Electrolytic properties}

\section{Results and Discussion}

Conductivity and viscosity of an electrolytic solution are of practical importance, because they determine the internal resistance, capacitance, and rate performance of the EDLC. Figure 1 shows (a) electric conductivities ( $\kappa$ ) and (b) dynamic viscosities $(\eta)$ of solutions containing quaternary ammonium salt (QA) as a function of the molar concentration $\left(c_{\mathrm{QA}}\right)$ at $25^{\circ} \mathrm{C}$. The solubility of TMADFOB in PC was $2 \mathrm{~mol} \mathrm{dm}^{-3}$ or more. The solubility of $\mathrm{TMABF}_{4}$ and $\mathrm{TEABF}_{4}$ is about 0.1 and $1 \mathrm{~mol} \mathrm{dm}^{-3}$, respectively, ${ }^{1)}$ and these values are much lower than the solubility of TEABOB. ${ }^{2-4)}$ The solubility of TMABOB is $0.9 \mathrm{~mol} \mathrm{dm}^{-3}{ }^{3,4)}$ The use of an asymmetric anion, DFOB-, exerted its effect. The crystal lattice energy of based on the asymmetric anion may be lower, and the solubility of the salt can greatly increase.

The electric conductivities increased to some extent with increasing the concentration of quaternary ammonium salt, because the number of charge carrier per unit volume increased. It should be noted that the molar concentration of the maximal conductivity of TMADFOB was as high as $1.6 \mathrm{~mol} \mathrm{dm}^{-3}$. The molar concentrations of the maximal conductivity were about $0.9,1$, and $1 \mathrm{~mol}$ $\mathrm{dm}^{-3}$ for TMABOB, TEABOB, and $\mathrm{TEABF}_{4}$, respectively. The electric conductivities of TMADFOB-based solutions were slightly lower than $\mathrm{TEABF}_{4}$-based counterparts throughout concentration measured. The electrolytic conductivities decreased in approximately the following descending order: $\mathrm{TEABF}_{4}>\mathrm{TMADFOB}_{\mathrm{T}}>>$ TEABOB $>$ TMABOB, which was the inverse order of the dynamic viscosity.

As a general rule, the electric conductivity can be
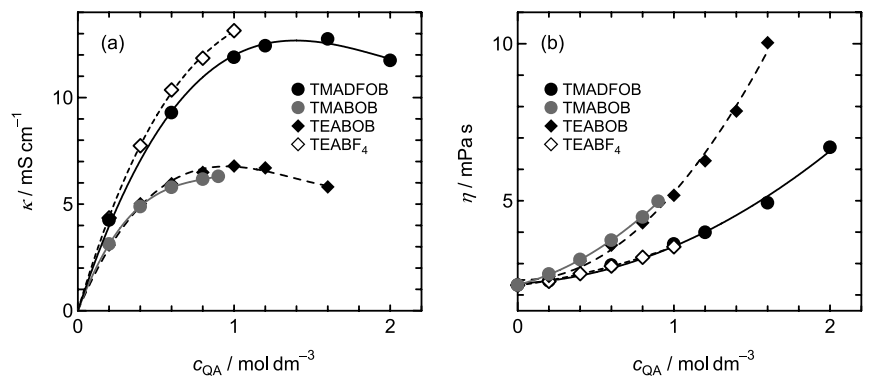

Fig. 1 (a) Electric conductivities ( $\kappa$ ) and (b) dynamic viscosities $(\eta)$ of $P C$ single solutions containing TMADFOB, TMABOB, TEABOB, or TEABF 4 as a function of the molar concentration $\left(c_{\mathrm{QA}}\right)$ at $25^{\circ} \mathrm{C}$. affected by the ionic mobility, the charge numbers of ions, the concentration of the electrolyte, and the degree of ionic dissociation of the salt. The ionic mobility relates to viscosity of the electrolytic solution, while the degree of ionic dissociation of the electrolyte depends on the permittivity of the medium. The dynamic viscosities of the electrolytic solutions increased with increasing the concentration of the quaternary ammonium salt, because the internal friction can increase. Therefore, the electric conductivity can adversely decrease in high concentration ranges.

\subsection{Cyclic voltammetry}

Integral single-electrode capacitance per unit mass of activated carbon $\left(C_{\mathrm{g}}{ }^{\text {int }}\right)$ can be calculated from cyclic voltammograms. Figure 2 shows cyclic voltammograms obtained for quaternary ammonium salt with activated carbon electrodes at a scan rate of $5 \mathrm{mV} \mathrm{s}^{-1}$. The molar concentrations of TMABOB, TMADFOB, TEABOB, and $\mathrm{TEABF}_{4}$ were adjusted to $0.9,1,1$, and $1 \mathrm{~mol} \mathrm{dm}^{-3}$, respectively. The maximal conductivity was observed around these concentrations except for TMADFOB, as described above. The electrode potential was changed from the rest potential in the positive direction, and the potential sweep was repeated three times between $+0.55 \mathrm{~V}$ and $-1.95 \mathrm{~V}$, where no significant decomposition of electrolyte cations, anions, and PC was proceeded. The cyclic voltammograms recorded at the third cycle are depicted in this figure. The values of the integral singleelectrode capacitance were determined to be 27.9, 27.6, 11.1, and $9.9 \mathrm{~F} \mathrm{~g} \mathrm{~g}^{-1}$ for TMADFOB, TEABF 4 , TEABOB, and TMABOB, respectively (Table 1 ). They were calculated according to $C_{\mathrm{g}}$ int $=Q /(E \cdot m)$, where $Q$ is the quantity of electricity corresponding to the half area of the cyclic voltammogram, $E$ is the width of the potential sweep $(2.5 \mathrm{~V})$, and $m$ is the dry mass of activated carbon. The gravimetric capacitance observed for TMADFOB

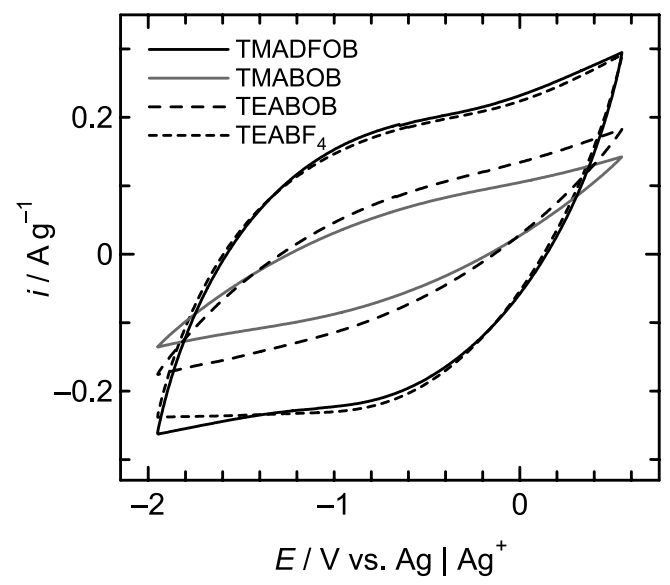

Fig. 2 Cyclic voltammograms recorded at the third cycle for TMADFOB, TMABOB, TEABOB, or $\mathrm{TEABF}_{4}$ with activated carbon electrodes at a scan rate of $5 \mathrm{mV} \mathrm{s}{ }^{-1}$ at 25 ${ }^{\circ} \mathrm{C}$. The molar concentrations of TMABOB, TMADFOB, TEABOB, and $\mathrm{TEABF}_{4}$ were adjusted to $0.9,1,1$, and $1 \mathrm{~mol}$ $\mathrm{dm}^{-3}$, respectively. The electrode potential was swept between +0.55 and $-1.95 \mathrm{~V}$ vs. $\mathrm{Ag} \mid \mathrm{Ag}^{+}$, and the width was set to $2.5 \mathrm{~V}$. 
was not only considerably higher than those for TMABOB and TEABOB, but also comparable to that for $\mathrm{TEABF}_{4}$. The highest gravimetric capacitance can be accounted for by the small size of $\mathrm{TMA}^{+}$and the planar structure of the oxalate moiety in $\mathrm{DFOB}^{-}$. The gravimetric capacitance obtained for quaternary ammonium salts based on symmetric anions decreased in the order of $\mathrm{TEABF}_{4}>\mathrm{TEABOB}>\mathrm{TMABOB}$. The finding indicates that bulk properties of the solution such as conductivity and viscosity are also dominant factors governing the capacitance..$^{2-4)}$ Mobility of moderately small ions is high in the bulk of the solution, and the ionic mobility may decrease in approximately the following descending order: $\mathrm{BF}_{4}^{-}>\mathrm{DFOB}^{-}>\mathrm{TEA}^{+}, \mathrm{TMA}^{+}>\mathrm{BOB}^{-}$.

\subsection{Charge and discharge characteristics of three- electrode measurement cells}

Furthermore, we evaluated integral single-electrode and integral full-cell capacitances per unit mass of activated carbon from the discharge curves of three-electrode measurement cells. The potentials of the positive and negative electrodes in the measurement cells were monitored separately with an $\mathrm{Ag} \mid \mathrm{Ag}^{+}$reference electrode. Figure 3(a) shows the charge and discharge curves of the three-electrode measurement cells using quaternary ammonium salt as an electrolyte at $25^{\circ} \mathrm{C}$. The molar concentrations of the quaternary ammonium salts are the same as in Fig. 2. Table 1 summarizes the gravimetric capacitances and $I R$ potential drops observed. The $I R$ potential drop is observed at the beginning of the $\mathrm{CC}$ discharge. The individual capacitances of the positive and the negative electrode were estimated from the reciprocals of the slopes of the discharge curves. Currents greatly decayed to low values during $\mathrm{CV}$ charge, as shown in Fig. 3(b). The results also suggest that no significant decomposition of electrolyte cations, anions, and $\mathrm{PC}$ is proceeded.

The moderate small ion size can account for the low $I R$ potential drop and the high gravimetric capacitance. While the measurement cell is charged, the surface excess concentrations of anions and cations increase at the positive and the negative electrode, respectively. The
$I R$ potential drop at the positive electrode was lower than that at the negative electrode. The gravimetric capacitance of the positive electrode $\left(C_{+, \mathrm{g}}\right.$ int $)$ was higher than that of the negative electrode $\left(C_{-,}\right.$int). The gravimetric capacitance of the positive electrode decreased in approximately the following descending order: $\mathrm{BF}_{4}{ }^{-}>$ $\mathrm{DFOB}^{-}>\mathrm{BOB}^{-}$. The gravimetric capacitance of the negative electrode observed for $\mathrm{TMA}^{+}$was higher than that for $\mathrm{TEA}^{+}$.

The integral total capacitance of the positive and negative electrodes connected in series $\left(C_{\text {total, }}{ }^{\text {int }}\right)$ can be readily calculated according to $1 /\left(2 C_{\text {total, }}\right.$ int $)=1 / C_{+, \text {git }}+1 /$ $C_{-, g}$ int. Therefore, the total gravimetric capacitance becomes considerably lower than the half of the decreased gravimetric capacitance of the negative electrode $\left(\mathrm{C}_{-, \mathrm{g}} / 2\right)$. The finding indicates that the ease with which quaternary ammonium ions move in and out of
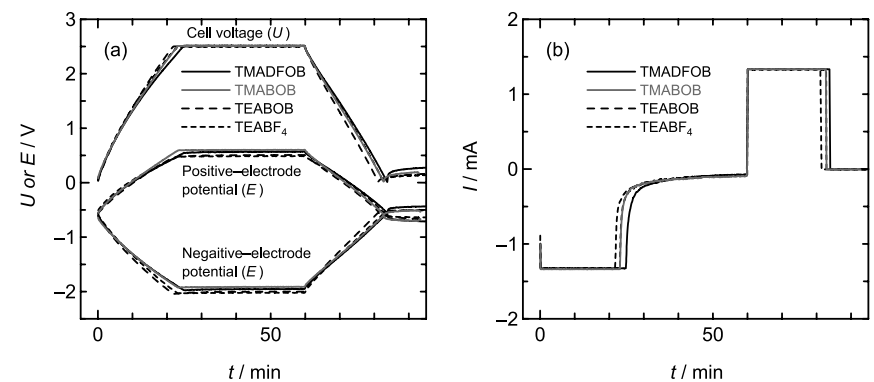

Fig. 3 (a) Charge and discharge curves of three-electrode measurement cells using TMADFOB, TMABOB, TEABOB, or $\mathrm{TEABF}_{4}$ as an electrolyte at $25{ }^{\circ} \mathrm{C}$. The molar concentrations of the quaternary ammonium salts are the same as in Fig. 2. The measurement cells were charged from 0 to $2.5 \mathrm{~V}$ in a constant-current (CC) $\left(-1 \mathrm{~mA} \mathrm{~cm}^{-2}\right.$, $-1.33 \mathrm{~mA}$ ) mode and further charged to keep constant voltage (CV) $(2.5 \mathrm{~V})$. Total charging time was set to $60 \mathrm{~min}$. The measurement cells were then discharged to $0 \mathrm{~V}$ at 1 $\mathrm{mA} \mathrm{cm}{ }^{-2}$. We have used a redox couple of $\mathrm{Ag} \mid \mathrm{Ag}^{+}$as the reference electrode for monitoring potentials of the positive and negative electrodes separately. (b) Current-time diagrams are also depicted.

Table 1 Comparison of integral single-electrode and integral total capacitances of activated carbon electrodes and $I R$ potential drops obtained for three-electrode measurement cells at $25{ }^{\circ} \mathrm{C}$ (Figs. 2 and 3). Electrolytic solutions: PC solutions containing TMADFOB, TMABOB, TEABOB, or TEABF 4 . The molar concentration of TMABOB was $0.9 \mathrm{~mol} \mathrm{dm}^{-3}$, and those of the other quaternary ammonium salts were adjusted to $1 \mathrm{~mol} \mathrm{dm}^{-3}$.

\begin{tabular}{|c|c|c|c|c|c|c|c|}
\hline \multirow{3}{*}{ Electrolyte } & \multicolumn{4}{|c|}{ Gravimetric capacitance / $\mathrm{F} \mathrm{g}^{-1}$} & \multicolumn{3}{|c|}{ IR potential drop / $\mathrm{mV}$} \\
\hline & \multirow{2}{*}{$\begin{array}{c}\text { Cyclic } \\
\text { voltammetry } \\
\left(5 \mathrm{mV} \mathrm{s}^{-1}\right) \\
\text { W. E. }\end{array}$} & \multicolumn{6}{|c|}{$\mathrm{CC}\left(-1 \mathrm{~mA} \mathrm{~cm}{ }^{-2}\right)-\mathrm{CV}(2.5 \mathrm{~V})$ charge followed by $\mathrm{CC}\left(1 \mathrm{~mA} \mathrm{~cm}^{-2}\right)$ discharge } \\
\hline & & Positive & Negative & Total & Positive & Negative & Total \\
\hline TMADFOB & 27.9 & 76.1 & 62.4 & 17.1 & 31.9 & 53.8 & 85.7 \\
\hline ТМАВОВ & 9.9 & 70.8 & 62.7 & 16.6 & 33.1 & 49.5 & 82.6 \\
\hline TEABOB & 11.1 & 72.5 & 52.8 & 15.3 & 18.6 & 101.3 & 119.9 \\
\hline $\mathrm{TEABF}_{4}$ & 27.6 & 78.8 & 57.1 & 16.6 & 21.2 & 88.3 & 109.5 \\
\hline
\end{tabular}


pores of the activated carbon negative electrode can be a key factor determining the total gravimetric capacitance. This is the reason why the total gravimetric capacitances obtained for TMADFOB is slightly higher than that for $\mathrm{TEABF}_{4}$. It should be noted that the charge and discharge characteristics of TMADFOB are in accord with the results of the cyclic voltammetry, but the same relation does not hold for both TMABOB and TEABOB. The gravimetric capacitance evaluated by cyclic voltammetry for TMADFOB was comparable to that obtained for $\mathrm{TEABF}_{4}$, while the gravimetric capacitances for TMABOB and TEABOB were considerably lower than for $\mathrm{TEABF}_{4}$. However, the total gravimetric capacitances determined by the discharge in a $\mathrm{CC}$ regime for the three quaternary ammonium salts were comparable to that for $\mathrm{TEABF}_{4}$. A very small distance between activated carbon electrodes in the measurement cell may compensate for lower ionic mobility of TMABOB and TEABOB in the PC solutions. ${ }^{2-4)}$

Potential-time curves of the positive and the negative electrode obtained for TMADFOB and TMABOB were slightly shifted in the positive directions. The observation supports idea that the use of $\mathrm{TMA}^{+}$as a counter cation increases the capacitance of the negative elec- trode, and accordingly the total capacitances are higher than that obtained for TEABOB.

\section{Conclusion}

TMADFOB is a novel tetramethylammonium salt based on an asymmetric chelate anion. TMADFOB has the potential of improving both the solubility in $\mathrm{PC}$ and the capacitance of EDLCs. It is very intriguing to investigate the performance of EDLCs at the higher concentration $\left(\sim 1.6 \mathrm{~mol} \mathrm{dm}^{-3}\right)$ of the maximal electric conductivity.

\section{References}

1) M. Ue, M. Takeda, M. Takehara, and S. Mori, J. Electrochem. Soc., 144, 2684 (1997).

2) N. Nanbu, T. Ebina, H. Uno, Y. Miyazaki, and Y. Sasaki, Electrochem. Solid-State Lett., 9, A482 (2006).

3) N. Nanbu, T. Ebina, H. Uno, S. Ishizawa, and Y. Sasaki, Electrochim. Acta, 52, 1763 (2006).

4) T. Ebina, H. Uno, S. Ishizawa, N. Nanbu, and Y. Sasaki, Chem. Lett., 34, 1014 (2005).

5) S. Tsujioka and H. Takase, Jpn. Kokai Tokkyo Koho, 137890 (2003) [in Japanese]. 